This item was submitted to Loughborough's Research Repository by the author.

Items in Figshare are protected by copyright, with all rights reserved, unless otherwise indicated.

\title{
Identifying MAIS3+ injury severity collisions in UK Police collision records
}

\section{PLEASE CITE THE PUBLISHED VERSION}

https://www.aaam.org/annual-conference/

\section{PUBLISHER}

Association for the Advancement of Automotive Medicine (AAAM)

\section{VERSION}

AM (Accepted Manuscript)

\section{PUBLISHER STATEMENT}

This work is made available according to the conditions of the Creative Commons Attribution-NonCommercialNoDerivatives 4.0 International (CC BY-NC-ND 4.0) licence. Full details of this licence are available at: https://creativecommons.org/licenses/by-nc-nd/4.0/

\section{LICENCE}

CC BY-NC-ND 4.0

\section{REPOSITORY RECORD}

Nunn, James, Jo Barnes, Andrew Morris, Emily S. Petherick, Roderick Mackenzie, and Matt Staton. 2019. "Identifying MAIS3+ Injury Severity Collisions in UK Police Collision Records". figshare.

https://hdl.handle.net/2134/35088. 


\section{TITLE}

Identifying MAIS3+ injury severity collisions in UK Police collision records.

\section{AUTHORS}

James Nunn. Loughborough University, Epinal Way, Loughborough, LE11 3TU, UK. J.Nunn@lboro.ac.uk Jo Barnes. Loughborough University, Epinal Way, Loughborough, LE11 3TU, UK. J.Barnes@lboro.ac.uk

Andrew Morris. Loughborough University, Epinal Way, Loughborough, LE11 3TU, UK. A.P.Morris@lboro.ac.uk Emily Petherick. Loughborough University, Epinal Way, Loughborough, LE11 3TU, UK. E.Petherick@lboro.ac.uk Roderick Mackenzie. Cambridge University Hospitals, Addenbrookes Hospital, Hills Road, Cambridge, CB2 0QQ, UK. Roderick.mackenzie@addenbrookes.nhs.uk

Matt Staton. Cambridgeshire County Council, Shire Hall, Castle Hill, Cambridge, CB3 0AP, UK

Matt.Staton@cambridgeshire.gov.uk.

\section{ABSTRACT}

\section{Objective}

This study represents the first stage of a project to identify serious injury, at the level of MAIS3+ (excluding fatal collisions) from within the police collision data. The resulting data will then be used to identify the vehicle drivers concerned and in later studies these will be culpability-scored and profiled to allow targeting of interventions.

\section{Method}

UK Police collision data known as STATS19 for the county of Cambridgeshire (UK) was linked using Stata with Trauma Audit and Research Network (TARN) hospital trauma patient data for the same geographical area for the period April 2012 to March 2017. Linking was two-stage; firstly, a deterministic process followed by a probabilistic process.

\section{Results}

The linked records represent an individual trauma patient from TARN data linked to an individual trauma casualty from STATS19 data. Full collision data for the incident resulting in the trauma casualty was extracted. The resulting subset of collisions has the MAIS3+ injury criteria applied. From the 10,498 recorded collisions the deterministic linking process was successful in linking 257 MAIS3+ trauma patients to collision injury subjects from 232 separate collisions with the probabilistic process linking a further 22 MAIS3+ subjects from 21 collision events. The combined collision data for the 253 collisions involved 434 motor vehicle drivers.

\section{Conclusions}

We produced viable results from the available data to identify MAIS3+ collisions from the overall collision data.

\section{KEYWORDS}

MAIS3+, Data, Linking, STATS19, Trauma Audit and Research Network (TARN), Collision

\section{INTRODUCTION}

Injury caused during road traffic collisions has a significant impact in the UK both in human and financial terms (Department for Transport 2017a, 2017b) and has a pronounced impact on younger adults (Office for National Statistics 2016, 2017). Most road collision injury reduction targets and interventions are based on the analysis of fatal collisions as these have a consistent definition; however, collisions are not homogenous events (Babarik 1968, McBain 1970, Ball and Owsley 1991, af Wåhlberg 2009). Targeting the reduction of serious injuries from road collisions is more problematic due to issues surrounding the defining of serious injury and assessment by non-medically trained reporting agents (Morris et al. 2006), currently in most cases a police officer with no formal medical training. The guidance requires the lay-interpretation of a list of example injuries which may be either 'serious' or 'slight' (Department for Transport 2011). The European Commission adopted the use of Maximum Abbreviated Injury Scale (MAIS) at a level of 3 and above to define serious injury in collisions; this is referred to as 'MAIS3+' (European Commission 2016) 
where casualties who have at least one 'serious' / Abbreviated Injury Scale 3+ injury can be defined as a MAIS3+ injury casualty. Intervention strategies tend to be targeted based on the epidemiology of the casualties, irrespective of their responsible for the collision. The overall study aim is to explore the feasibility of targeting intervention strategies at drivers who have caused the serious injury collision, whether they are injured or not. The first stage of the study is to identify the collisions, and hence the drivers who have been involved in a MAIS3+ injury collision using data linkage methodology to link police collision records to hospital injury records. The goal for the data linkage was to produce a dataset containing the full collision data for collisions whereby a MAIS3+ injury occurred but was not fatal allowing the drivers involved in the collisions to be identified and the collision circumstances to be analysed.

\section{METHODS}

STATS19 police collision data for the county of Cambridgeshire, UK for the period April 2012 to March 2017 identified 10,498 injury collision incidents. The police injury severity classification was 'fatal' ( $\mathrm{n}=158$ collisions, $\mathrm{n}=174$ casualties), 'serious' ( $n=1593$ collisions, $n=1823$ casualties) and 'slight' ( $n=8754$ collisions, $n=12,104$ casualties). The STATS19 data contained 23,741 individual records relating to a subject involved in the collisions. To identify the medical severity of the casualties involved in the collision it was necessary to link STATS19 to anonymised hospitalbased Trauma Audit and Research Network (TARN) data from Cambridge University Hospitals. All TARN data is coded by trained coders from medical records using the AIS (2005) edition. TARN data for 1,907 patients injured in road traffic collisions over the same period for the six counties forming the East of England region was available for matching to the STATS19 data. The record-linking function within Stata was used for the processes. There was no common unique identifier, so after standardisation of the data fields, a primary deterministic record linkage process was undertaken using the four common variables (sex, age, date of incident and the first part of the postal code). The first phase of the linkage required absolute matches between the datasets on all four common variables. Following removal of these matches, a secondary probabilistic record linkage process was undertaken using variation in 'age' by plus or minus 5 years, achieved by varying the variable weighting. The function of the probabilistic process was to pick up records where the subject's age had been estimated by the reporting agent and therefore records were matched if there was a positive or negative 5-year variation if all other variables were correct. It was not expected to produce a significant number of responses compared to the deterministic process. Once data linkage was complete, the STATS19 collision reference was used to identify all parties involved in the collision and subsequently identify the drivers of the vehicles involved (irrespective of injury status). Once the drivers of vehicles involved in the collisions were identified, records were filtered to only include collision records where a MAIS3+ injury had been reported.

\section{RESULTS}

The linking of the data has successfully identified collisions from the police data corresponding to patients with a 'serious' MAIS3+ injury and enabled the drivers to be identified. The collision data for 2012-2017 contained 10,498 collisions involving records from 23,741 individuals, either drivers or injured parties. The TARN data for 2012-2017 contained 1,907 observations from individual patients. The deterministic process resulted in a total to 295 linked records of which 257 were MAIS3+. These resulted from 232 separate collision incidents, involving 399 motor vehicle drivers. The probabilistic linkage resulted in a further 31 matches of which 22 were MAIS3+. These resulted from 21 collision incidents involving 35 motor vehicle drivers. There were no multiple matches in either process. The record linkage process resulted in a total of 434 drivers who were involved in a collision where at least one person had sustained a serious MAIS3+ injury.

\section{DISCUSSION}

Linking police and health datasets has enabled the identification of 'serious' injury collisions at the MAIS3+ severity and subsequently the corresponding drivers involved in these incidents. The numbers of MAIS3+ casualties are 
considerably lower than the number of serious injury casualties recoded by the reporting agents, reinforcing the questioning of the accuracy of non-medically trained injury severity assessment. The production of a subset of collisions containing the MAIS3+ injury incidents also allows for the analysis of the circumstantial material. The understanding of these factors, such as, the type of road, junction detail, time of the collision, day, month and so on will allow the development of evidence underpinning collisions, which can inform future intervention strategies.

The next phase of the study is to culpability-score the drivers in these collisions. Ultimately it is expected that this study will allow for targeting road safety interventions at drivers who cause serious MAIS3+ injurious collisions. The data linkage methodology will further enable comparisons to be made to drivers causing fatal crashes and consideration of further population-based road safety interventions. Moreover, it is envisaged that the methods can be applied to a wider geographical area in the UK.

\section{ACKNOWLEDGEMENTS}

The authors would like to thank Cambridgeshire County Council and Cambridgeshire Constabulary for facilitating access to the STATS19 police collision data, Cambridge University Hospitals for facilitating access to the TARN hospital trauma patient data from for road traffic injuries for the East of England and the Road Safety Trust for providing funding for the project.

\section{REFERENCES}

1 Babarik P. Automobile Accidents and Driver Reaction Pattern, J Appl Psychol. 1968; 52(1):49-54.

2 Ball K, Owsley C. Identifying Correlates of Accident Involvement for the Older Driver', Hum Factors, 1991; 33(5):583-595.

3 Department for Transport. STATS20: Instructions for the Completion of Road Accident Reports from non-CRASH Sources. Available at: https://www.gov.uk/government/uploads/system/uploads/attachment_data/file/230596/stats202011.pdf . 2011. Accessed: 18 July 2017.

4 Department for Transport. Average value of prevention per reported casualty and per reported road accident GB 2016. https://www.gov.uk/government/statistical-data-sets/ras60-average-value-of-preventing-road-accidents . 2017a.

Accessed: 9 July 2018.

5 Department for Transport. Reported Road Casualties in Great Britain: 2016 annual report.

https://www.gov.uk/government/uploads/system/uploads/attachment_data/file/648081/rrcgb2016-01.pdf . $2017 \mathrm{~b}$.

Accessed: 9 July 2018.

6 European Commission. Study on Serious Road Traffic Injuries in the EU.

https://ec.europa.eu/transport/road_safety/sites/roadsafety/files/injuries_study_2016.pdf . 2016. Accessed: 9 July 2018.

7 McBain WN. Arousal, Monotony, and Accidents in Line Driving. J Appl Psychol. 1970; 54(6):509-519.

8 Morris A, Mackey M, Wodzin E, Barnes J. Some injury scaling issues in UK crash research. International IRCOBI Conference on the Biomechanics of Impact, IRCOBI, Lisbon, Portugal 24-26 September, 2003, 2006:283-291.

9 Office for National Statistics. Deaths registered in England and Wales (Series DR): 2015.

https://www.ons.gov.uk/peoplepopulationandcommunity/birthsdeathsandmarriages/deaths/bulletins/deathsregisteredine nglandandwalesseriesdr/2015 .2016. Accessed: 9 July 2018.

10 Office for National Statistics. Avoidable mortality in England and Wales: 2015.

https://www.ons.gov.uk/peoplepopulationandcommunity/healthandsocialcare/causesofdeath/bulletins/avoidablemortalit yinenglandandwales/2015 . 2017. Accessed: 9 July 2018.

11 af Wåhlberg AE. Driver Behaviour and Accident Research Methodology: Unresolved problems. Farnham, Surrey: Ashgate Publishing Limited; 2009. 